\title{
CD90 determined two subpopulations of glioma-associated mesenchymal stem cells with different roles in tumour progression
}

\author{
Qing Zhang ${ }^{1}$, Dong-Ye Yi ${ }^{1}$, Bing-Zhou Xue', Wan-Wan Wen², Yin-Ping Lu ${ }^{3}$, Ahmed Abdelmaksou ${ }^{1,4}$, Min-Xuan Sun ${ }^{5}$, \\ De-tian Yuan ${ }^{5}$, Hong-Yang Zhao ${ }^{1}$, Nan-Xiang Xiong ${ }^{1}$, Wei Xiang ${ }^{1}$ and Peng Fu ${ }^{1}$
}

\begin{abstract}
Human glioma-associated mesenchymal stem cells (gbMSCs) are the stromal cell components that contribute to the tumourigenesis of malignant gliomas. Recent studies have shown that gbMSCs consist of two distinct subpopulations $\left(\mathrm{CD}{ }^{+}\right.$and $\mathrm{CD} 90^{-}$gbMSCs). However, the different roles in glioma progression have not been expounded. In this study, we found that the different roles of gbMSCs in glioma progression were associated with CD90 expression. CD90 high $\mathrm{gbMSCS}$ significantly drove glioma progression mainly by increasing proliferation, migration and adhesion, where as $\mathrm{CD} 90^{\text {low }}$ gbMSCs contributed to glioma progression chiefly through the transition to pericytes and stimulation of vascular formation via vascular endothelial cells. Furthermore, discrepancies in long non-coding RNAs and mRNAs expression were verified in these two gbMSC subpopulations, and the potential underlying molecular mechanism was discussed. Our data confirm for the first time that CD $90^{\text {high }}$ and $C D 90^{\text {low }}$ gbMSCs play different roles in human glioma progression. These results provide new insights into the possible future use of strategies targeting gbMSC subpopulations in glioma patients.
\end{abstract}

\section{Introduction}

Gliomas are the primary central nervous system tumours with the highest incidence despite progress made in combination treatment using surgical, radiotherapy and chemotherapy approaches ${ }^{1,2}$. Better understanding of the tumour microenvironment will enable pursuit and development of a promising therapeutic strategy for gliomas ${ }^{3,4}$.

Generally, the tumour microenvironment consists of tumour cells, fibroblasts, endothelial cells, mesenchymal stem cell (MSCs), and inflammatory cells as well as

\footnotetext{
Correspondence: Wei Xiang (xiangwei20@hotmail.com) or Peng Fu (pfu@hust. edu.cn)

${ }^{1}$ Department of Neurosurgery, Union Hospital, Tongji Medical College, Huazhong University of Science and Technology, Wuhan 430022, China 2Department of Cardiology, Beijing Anzhen Hospital, Capital Medical University, No. 2, Anzhen Road, Chaoyang District, Beijing 100029, China Full list of author information is available at the end of the article. These authors contributed equally: Qing Zhang, Dong-Ye Yi Edited by $Y$. Shi
}

cytokines and chemokines secreted by tumour and stromal cells ${ }^{3}$. In gliomas, MSCs can be recruited by some factors into the tumour microenvironment and modulate tumour development ${ }^{5}$. Our team reported that gliomaassociated MSCs (gbMSCs) had classical MSC surface markers (CD105, CD73, CD90 and CD44) but lacked expression of CD14, CD34 and CD45. Gb-MSCs show plastic adherent morphology and have the capacity to differentiate into osteoblasts, adipocytes and chondroblasts in vitro ${ }^{6,7}$. The percentage of gbMSCs in high-grade glioma samples is closely related to their survival within GBM patients ${ }^{8}$. Furthermore, we found that human gbMSCs were integral components in the pericyte transition and tumour vascular formation. ${ }^{6}$ Some reports have demonstrated that gbMSCs can increase glioma stem cell self-renewal and proliferation via secretion of exosomes and factors. ${ }^{9}$

Recent reports found that gbMSCs could be divided into two subtypes according to CD90 expression

\section{(c) The Author(s) 2018}

(c) (i) Open Access This article is licensed under a Creative Commons Attribution 4.0 International License, which permits use, sharing, adaptation, distribution and reproduction c. in any medium or format, as long as you give appropriate credit to the original author(s) and the source, provide a link to the Creative Commons license, and indicate if changes were made. The images or other third party material in this article are included in the article's Creative Commons license, unless indicated otherwise in a credit line to the material. If material is not included in the article's Creative Commons license and your intended use is not permitted by statutory regulation or exceeds the permitted use, you will need to obtain permission directly from the copyright holder. To view a copy of this license, visit http://creativecommons.org/licenses/by/4.0/. 
Table1 Characteristics of 14 patients with gliomas used for gbMSC isolation in the current study

\begin{tabular}{|c|c|c|c|c|c|c|}
\hline Specimen & Age (years) $)^{a}$ & Sex & Pathological diagnosis & Grade & Passage at experiment & CD90 expression in gbMSCs (\%) \\
\hline$A C-11$ & 29 & M & Astrocytoma & III & 3 & 20.1 \\
\hline GBM-13 & 53 & $\mathrm{~F}$ & GBM & IV & 2 & 21.3 \\
\hline$A C-16$ & 58 & $\mathrm{~F}$ & Astrocytoma & III & 2 & 19.2 \\
\hline ODG-18 & 36 & M & Oligodendroglioma & $\|$ & 3 & 13.5 \\
\hline GBM-21 & 35 & $\mathrm{~F}$ & GBM & IV & 2 & 21.7 \\
\hline GBM-23 & 59 & M & GBM & IV & 3 & 25.9 \\
\hline$A C-24$ & 45 & M & Astrocytoma & III & 3 & 18.9 \\
\hline GBM-31 & 58 & M & GBM & IV & 3 & 19.8 \\
\hline GBM-32 & 56 & M & GBM & IV & 4 & 23.8 \\
\hline$A C-35$ & 62 & $\mathrm{~F}$ & Astrocytoma & $\|$ & 2 & 17.9 \\
\hline GBM-35 & 79 & $\mathrm{~F}$ & GBM & IV & 2 & 22.1 \\
\hline GBM-71 & 61 & $\mathrm{~F}$ & GBM & IV & 4 & 20.3 \\
\hline AC-73 & 36 & $\mathrm{~F}$ & Astrocytoma & III & 3 & 19.8 \\
\hline AV-76 & 38 & M & Astrocytoma & IV & 2 & 21.5 \\
\hline
\end{tabular}

${ }^{\mathrm{a} A t}$ the time of diagnosis

$\left(\mathrm{CD} 90^{+}\right.$gbMSCs and $\mathrm{CD}^{-}$gbMSCs). $\mathrm{CD}^{-}{ }^{-}$cells are regarded as more active in glioma vascularization and immunosuppression than their $\mathrm{CD}^{+} 0^{+}$counterparts, and $\mathrm{CD}^{-} 0^{-}$and $\mathrm{CD}^{+} 0^{+}$gbMSCs differ greatly in their mRNA expression patterns ${ }^{10}$. However, the biological properties of these two distinct subpopulations and their effects on glioma have not been fully elaborated.

In this study, we elaborately sorted two distinct MSClike cell populations from gbMSCs according to differences in CD90 surface marker expression and investigated the different roles of these two gbMSC subpopulations in glioma progression.

\section{Materials and methods}

\section{Tumour samples}

Human brain tumour samples were obtained from the Neurosurgery Department at Union Hospital in Wuhan, China, after patients with glioma provided informed consent. The specimens were reviewed by a neuropathologist to assess the grade and tumour type before the assays were performed (Table1). Typically, cell separation was performed within $1 \mathrm{~h}$ of tumour resection.

\section{Isolation and culture of human gbMSCs}

The sample was transferred to a Petri dish, washed three times in phosphate-buffered saline (PBS, HyClone, USA), and cut into $1-\mathrm{mm}^{3}$ pieces. Next, $0.25 \%$ trypsin (BIYUNTIAN, China) was added to the tumour specimens. Then, the single pieces were digested for $20 \mathrm{~min}$, filtered with a 70- $\mu \mathrm{m}$ nylon mesh (Corning, USA) and centrifuged at $1000 \mathrm{rpm}$ for $15 \mathrm{~min}$. The mononuclear cells were collected by Ficoll (2:1 Genview, USA) density gradient centrifugation at $1500 \mathrm{rpm}$ for $20 \mathrm{~min}$ without braking. Single cells were re-suspended in DMEM (HyClone, USA) containing 10\% foetal bovine serum (BI, Israel) and $100 \mathrm{U} / \mathrm{ml}$ of penicillin/streptomycin (GibcoBRL, Grand Island, NY, USA), seeded into a $25-\mathrm{cm}^{2}$ culture flask (Corning, USA) and incubated at $37^{\circ} \mathrm{C}$ and humidity with $5 \% \mathrm{CO}_{2}$. The medium was changed 1-3 times every week. Cells at 70-80\% confluency were passaged using Accutase (StemCell, Canada) and used for experiments at passages 2 to 3 .

\section{Cell lines}

U87-MGs were purchased from the American Type Culture Collection (ATCC, Gaithersburg, MD, USA), and human umbilical vein endothelial cells (HUVECs) were purchased from Lonza (MD, USA). The U87-MGs and HUVECs were cultured in Dulbecco's modified Eagle's medium (DMEM) (HyClone, USA) and RPMI 1640 medium (Gibco, USA), respectively, supplemented with $10 \%$ foetal bovine serum (FBS; BI, Israel) and $100 \mathrm{U} / \mathrm{ml}$ of penicillin/streptomycin (GibcoBRL, Grand Island, NY, USA) in humidified atmosphere at $37{ }^{\circ} \mathrm{C}$ with $5 \% \mathrm{CO}_{2}$.

\section{Conditioned media}

For all experiments, U87-MGs, CD90 ${ }^{\text {high }}$ gbMSCs and CD90 ${ }^{\text {low }}$ gbMSCs were seeded into T25 tissue culture flasks in DMEM with 10\%FBS containing penicillin $(100 \mathrm{U} / \mathrm{mL}) /$ streptomycin $\quad(100 \mathrm{mg} / \mathrm{mL}) \quad$ (GibcoBRL, 
Grand Island, NY, USA). When the cell density reached $50-60 \%$ confluency, the medium of the U87-MGs was replaced with serum-free medium (DMEM) and DMEM supplemented with $10 \% \mathrm{FBS}$, the medium of the CD $90^{\text {high }}$ and $\mathrm{CD} 90^{\text {low }}$ gbMSCs was replaced with serum-free medium (DMEM), and the cells were cultured for $72 \mathrm{~h}$. Conditioned media were collected from the flasks and centrifuged at $1000 \times g$ for $10 \mathrm{~min}$ to remove cells and cellular debris. Afterward, the collected conditioned media $\left(\mathrm{CD} 90^{\text {high }} \mathrm{CM}\right.$, CD90 ${ }^{\text {low }} \mathrm{CM}$, 0\%gb-CM, and S-gb$\mathrm{CM})$ were stored at $-20{ }^{\circ} \mathrm{C}$ prior to use.

\section{Differentiation of gbMSCs}

The gbMSCs were adipogenically, osteogenically and chondrogenically induced using ready-to-use differentiation media (all from Stemcell, Canada) following the manufacturer's instructions. Adipogenic differentiation was evaluated by oil red $\mathrm{O}$ staining, osteogenic differentiation was evaluated by Alizarin red staining and chondrogenic differentiation was evaluated by Alcian blue staining (all from Sigma, USA). The specific steps were as follows.

For osteoblast differentiation, the cells were cultured in growth medium in a six-well plate and incubated at $37^{\circ} \mathrm{C}$ with $5 \% \mathrm{CO}_{2}$ until they were approximately $70-80 \%$ confluent. Next, the medium was replaced by complete osteogenic stimulatory medium, the cells were incubated at $37^{\circ} \mathrm{C}$ and the medium was changed every 3 days. The differentiation assay took approximately 3 weeks. Osteogenic differentiation was visualized by Alizarin red $S$ staining.

For adipocyte differentiation, the cells were cultured in standard medium in a six-well plate at $37^{\circ} \mathrm{C}$ and $5 \% \mathrm{CO}_{2}$ until they were approximately $90-100 \%$ confluent. Then, the medium was aspirated and replaced with complete adipogenic differentiation medium, which was changed every 3 days. The differentiation assay took approximately 14 days. Adipogenic differentiation was visualized by oil red O staining.

For chondrocyte differentiation, cell pellets were grown in chondrogenesis induction medium for 21 days, and half of the medium was changed during differentiation. Histological sections of the pellet were generated by fixing the pellets in $10 \%$ formalin for $30 \mathrm{~min}$ at room temperature $\left(15-25^{\circ} \mathrm{C}\right)$, followed by subsequent standard paraffin embedding methods and staining of $6-\mu \mathrm{m}$-thick sections with Alcian blue.

\section{Magnetic activated cell sorting (MACS) of the gbMSCs}

gbMSCs grown in good condition were used for the MACS experiment. First, the cells were immuno-labelled with CD90 microbeads (Miltenyi, Germany). Magnetic labelling was performed strictly according to the manufacturer's instructions. Briefly, the gbMSCs were digested using Accutase (Stemcell, Canada) and centrifuged at $1500 \mathrm{rpm}$ for $6 \mathrm{~min}$. The cell pellet was re-suspended in $80 \mu \mathrm{L}$ of precooled sorting buffer per $10^{7}$ total cells, and $20 \mu \mathrm{L}$ of CD90 MicroBeads was added per $10^{7}$ total cells. Then, the solution was mixed well and incubated for $15 \mathrm{~min}$ in the dark in the refrigerator $\left(2-8^{\circ} \mathrm{C}\right)$. The cells were washed by adding $2 \mathrm{~mL}$ of buffer per $10^{7}$ cells and centrifuged at $1500 \mathrm{rpm}$ for $6 \mathrm{~min}$. The supernatant was aspirated completely. The cells were re-suspended in $500 \mu \mathrm{L}$ of sorting buffer. Magnetic separation was performed using the autoMACS Pro Separator (Miltenyi, Germany).Ultimately, we obtained CD90 ${ }^{\text {high }}$ gbMSCs and CD90 ${ }^{\text {low }}$ gbMSCs.

\section{Flow cytometry}

Flow cytometry analysis was performed using fluorochrome-conjugated antibodies. Briefly, different passages of gbMSCs, CD $90^{\text {high }}$ gbMSCs and CD90 ${ }^{\text {low }}$ gbMSCs were trypsinized and washed in PBS, and then the pellets were re-suspended in fluorescent-activated cell sorting (FACS) buffer. These single-cell suspensions were incubated in the dark at $4{ }^{\circ} \mathrm{C}$ for $30 \mathrm{~min}$ with PE-, FITC-, PE-Cy7-, APC-Cy7-,PerCP- and APC-conjugated antibodies against human CD73, CD105, CD90, CD44, CD13, CD34, CD31, Desmin, $\alpha$-SMA (from eBioscience, USA), NG2 and PDGFR- $\beta$ (from R\&D Systems, USA). Then, the cells were centrifuged, re-suspended in PBS and analysed using a flow cytometer (BD Biosciences). The data were collected and analysed using the FlowJo (TreeStar, Ashland, OR, USA) software.

\section{Cell proliferation assay}

Cell viability was analysed using the Cell Counting kit-8 (CCK-8 Kit, Dojindo Laboratories, Japan). U87 cells (3000/well) was seeded into a 96-well plate and cultured overnight. Then, the medium was replaced with $100 \mu \mathrm{l}$ of serum-free medium (0\%DMEM), serum-free CD $90^{\text {high }}$ gbMSC-conditioned medium (CD90 $\left.{ }^{\text {high }} \mathrm{CM}\right)$, or serumfree $\mathrm{CD} 90^{\text {low }}$ gbMSC-conditioned medium $\left(\mathrm{CD} 90^{\text {low }} \mathrm{CM}\right)$ and cultured for $1,2,3$, or 4 days.CD $90^{\text {low }}$ and CD90high gbMSCs were seeded into $100 \mu \mathrm{l}$ of serum-free medium supplemented with 10\% FBS (10\%DMEM) and cultured for $1,2,3$, or $4 \mathrm{~h}$. At various time points, $10 \mu \mathrm{l}$ of CCK-8 was added to each well and incubated for $2 \mathrm{~h}$ at $37^{\circ} \mathrm{C}$ with $5 \% \mathrm{CO}_{2}$. Then, the absorbance of each well was measured at $450 \mathrm{~nm}$ using a microplate reader (PerkinElmer, USA). At least three wells were used for each sample in different media. The assays were repeated at least three times.

\section{Adhesion assay}

U87 cells were treated with $\mathrm{CD} 90^{\text {high }} \mathrm{CM}$ and $\mathrm{CD} 90^{\text {low }}$ $\mathrm{CM}$ for $48 \mathrm{~h}$. Then, the cells were seeded at a density of $1 \times 10^{4}$ cells/well in 96-well plates pre-coated with matrix 
adhesive and incubated with $0 \%$ DMEM, CD90 ${ }^{\text {high }} \mathrm{CM}$ and $\mathrm{CD} 90^{\text {low }} \mathrm{CM}$ for $1 \mathrm{~h}$ at $37^{\circ} \mathrm{C}$ in an atmosphere enriched with $5 \% \mathrm{CO}_{2}$. The non-adherent cells were removed by washing carefully three times with PBS, and the cultures were incubated in $100 \mu \mathrm{l}$ of medium with 10 $\mu \mathrm{l}$ of CCK8 (Dojindo Laboratories, Japan) for $2 \mathrm{~h}$. Cell adhesion was analysed by measuring the optical density (OD) at $450 \mathrm{~nm}$ in a microplate reader (PerkinElmer, USA). At least three wells were used for each sample in different media. The assays were repeated at least three times.

\section{Migration assays \\ Transwell chamber assay}

The migration capacity of the U87 cells was evaluated in 24-well plates with Transwell inserts with an $8-\mu \mathrm{m}$ pore size (BD FALCON, USA). U87 cells $\left(5 \times 10^{4} / \mathrm{ml}\right)$ in $100 \mu \mathrm{l}$ of serum-free DMEM were added to the upper chamber, and $800 \mu \mathrm{l}$ of the tested samples (0\%DMEM, $\mathrm{CD} 90^{\text {high }} \mathrm{CM}$ and $\mathrm{CD} 90^{\text {low }} \mathrm{CM}$ ) was placed in the lower chambers. Cell migration was allowed for $24 \mathrm{~h}$ at $37^{\circ} \mathrm{C}$ with $5 \% \mathrm{CO}_{2}$. Following incubation, the media were aspirated, and the cells remaining on the upper surface of the polycarbonate membrane were removed with a cotton swab. The cells that migrated to the lower surface were stained with Giemsa for $20 \mathrm{~min}$. Cell counting was performed under an inverted microscope by two researchers independently. The average numbers of migrated cells were determined by counting the cells in 5 random high-power fields (x200).

\section{Wound-healing assay}

A wound-healing assay was used to evaluate the migration ability of the CD90 $0^{\text {high }}$ and $\mathrm{CD} 90^{\text {low }}$ gbMSCs in different media in vitro. The cells were incubated in 6-well plates until they reached $90-100 \%$ confluence. Then, cross lines were carefully made using a 10- $\mu \mathrm{l}$ pipette tip, and the debris was washed away with PBS. The medium was replaced with serum-free medium (0\%DMEM), standard medium (10\%DMEM), serum-free glioblastoma-conditioned medium (0\%gb-CM) and standard glioblastoma-conditioned medium (S-gb-CM). The areas of the scratch wounds were photographed with an Olympus microscope at 0 and $8 \mathrm{~h}$. The assays were performed in triplicate at least three times, and the data were analysed using the Image $J$ software (NIH, USA).

\section{Immunochemistry and Immunofluorescence}

For immunochemistry, tumour tissue specimens were fixed in $4 \%$ paraformaldehyde and embedded in paraffin after collection from sacrificed mice. The tissue sections were cut and dewaxed, and then antigens were retrieval. The slides were rinsed in PBS, incubated overnight at $4{ }^{\circ} \mathrm{C}$ with diluted anti-CD31 (1:50) and anti-Ki67 (1:800) antibodies (Proteintech, WuHan, China), and then incubated with an HRP-conjugated secondary antibody (1:1, Boster, WuHan, China). Binding was detected using a DAB solution (Boster, WuHan, China). The tissues were counterstained using haematoxylin (Boster, WuHan, China). Images of the stained tissue samples were obtained using an Olympus microscope.

For immunofluorescence, human GBM surgical specimens were harvested and fixed with $4 \%$ paraformaldehyde, and sections were prepared for immunostaining. Nonspecific staining was blocked by pre-incubation of these sections in goat serum diluted with PBS for $30 \mathrm{~min}$ at room temperature. The primary antibodies used were as follows: goat anti-CD105 polyclonal antibody (1:25, R\&D Systems, USA) and rabbit anti-CD90 monoclonal antibody (1:25, Boster, WuHan, China). After incubation with the primary antibody overnight at $4{ }^{\circ} \mathrm{C}$, the sections were rinsed several times with PBS and incubated with the appropriate secondary antibodies at room temperature for $1 \mathrm{~h}$. The secondary antibodies used were as follows: Cy3-conjugated goat antirabbit and FITC-conjugated goat anti-goat antibodies (1:100, all from Boster, WuHan, China). After washing in PBS, the sections were counterstained with DAPI (Beyotime, WuHan, China) and mounted with antifade mounting medium. Immunofluorescence microscopy was performed with an Olympus microscope.

\section{Tube formation assay}

Growth factor-reduced Matrigel (BD, USA) was added to a flat-bottomed, pre-cooled, 96-well plate. After incubation at $37^{\circ} \mathrm{C}$ with $5 \% \mathrm{CO}_{2}$ for $1 \mathrm{~h}$. CD $90^{\text {high }}$ and $\mathrm{CD} 90^{\text {low }}$ gbMSCs were labelled using Calcein AM (Tocris, USA) and DiO (Yeasen, Shanghai, China). Calcein AM-labelled CD90 $0^{\text {high }}$ and $\mathrm{CD} 90^{\text {low }}$ gbMSCs were seeded $\left(2 \times 10^{4} /\right.$ well $)$ into wells containing serumfree medium (0\%DMEM), standard medium (10\% DMEM), serum-free glioblastoma-conditioned medium (0\%gb-CM) or standard glioblastoma-conditioned medium (S-gb-CM). HUVECs $\left(2 \times 10^{4} /\right.$ well) were seeded into wells containing $0 \% \mathrm{DMEM}, \mathrm{CD} 90^{\text {high }} \mathrm{CM}$ and $\mathrm{CD} 90^{\text {low }}$ CM. The HUVECs $\left(2 \times 10^{4} /\right.$ well $)$ were co-cultured with DiO-labelled $\mathrm{CD} 90^{\text {high }}$ and $\mathrm{CD} 90^{\text {low }}$ gbMSCs $\left(1 \times 10^{4} /\right.$ well $)$ in wells containing serum-free glioblastoma-conditioned medium (0\%gb-CM). Then, the 96-well plate was incubatedat $37^{\circ} \mathrm{C}$ in $5 \% \mathrm{CO}_{2}$. Three wells were used for each medium sample. After $6 \mathrm{~h}$, tube formation was photo documented with an Olympus microscope. Capillary-like tube formation and the attachment of $\mathrm{CD} 90^{\text {high }}$ and $\mathrm{CD} 90^{\text {low }}$ gbMSCs onto the HUVECs were analysed in three random fields of view per well using the ImageJ software (NIH, USA). 


\section{ELISA assay}

The VEGF, bFGF, SDF- $1 \alpha$, CCL5, MMP9 and IL-6 levels in the supernatants of each medium sample (0\%DMEM, CD90 ${ }^{\text {high }} \mathrm{CM}$ and $\mathrm{CD} 90^{\text {low }} \mathrm{CM}$ ) were measured using their respective ELISA kits (Neobioscience, China). All procedures were performed as described in the manufacturer's instructions. The absorbance was measured at $450 \mathrm{~nm}$. Three wells were used for each medium sample.The assays were repeated three times.

\section{RNA extraction and Clariom D microarray}

CD $90^{\text {high }}$ and CD $90^{\text {low }}$ gbMSCs were cultured in standard medium until approximately $90 \%$ confluent. Total RNA was extracted from three different batches of CD $90^{\text {high }}$ gbMSCs and three corresponding $\mathrm{CD} 90^{\text {low }}$ gbMSCs cultured in standard medium using the TRIzol reagent (Invitrogen, USA). After the total RNA quality was analysed with a NanoDrop (Thomas Fisher Scientific), cDNA was prepared using the GeneChip WT PLUS Kit and hybridized onto Affymetrix GeneChip ${ }^{\circledR}$ Clariom D arrays (Affymetrix, Santa Clara, CA, USA), which were washed and scanned according to Affymetrix's instructions (Fluidics Protocol FS450_0003). The microarray data were measured and summarized using the Clariom D QC tool software (Affymetrix, Santa Clara, CA, USA).

\section{In vivo experiment}

Male BALB/c-nu mice (4-6 weeks old; Beijing Vital River Laboratory Animal) were kept in the animal facilities at Huazhong University of Science and Technology and maintained under specific pathogen-free conditions. Intraperitoneal (IP) injections of chloral hydrate $(2.5 \mathrm{ml} / \mathrm{kg})$ were used to anaesthetize the animals in all experiments. All animal procedures were conducted in accordance with institutional guidelines under approved protocols. For the intracranial implantation of syngeneic U87 glioma cells in the brains of the BALB/c-nu mice, the animals were stereotactically inoculated with a $\mathrm{CD} 90^{\text {high }} \mathrm{CM}$ or $\mathrm{CD} 90^{\text {low }}$ $\mathrm{CM}$ suspension containing $5 \times 10^{5}$ U87 cells into the right frontal lobe $(2 \mathrm{~mm}$ lateral and $1 \mathrm{~mm}$ anterior to the bregmaat a 3.5-mm depth from the skull base) using a Hamilton syringe (Hamilton Company, USA). The mice were sacrificed 28 days after injection. The tumour volumes of the nude mice in each group were calculated as $V=1 / 2 L W^{2}(L$ $=$ tumour length, $W=$ tumour width).

Additionally, we took advantage of the full list of available datasets presented on the GlioVis homepage (http:// gliovis.bioinfo.cnio.es/) to analyse the overall survival of patients with gliomas in groups with differing CD90 expression levels from TCGA GBM dataset.

\section{Statistical analysis}

The statistical analyses were performed with GraphPad Prism. Unless specifically noted, all data were representative of at least three separate experiments. Error bars represent the standard deviations (SDs) and were calculated using Prism. The specific statistical tests used were a $t$ test for single comparisons or ANOVA followed by Tukey's test for multiple comparisons, and all $P$ values $<0.05$ were considered statistically significant. GraphPad Prism was used to compare two survival curves with the log-rank test.

\section{Results \\ Characteristics of CD90 high and CD90 ${ }^{\text {low }}$ gbMSCs}

gbMSCs were successfully isolated from fresh tumour tissues from patients with different grade gliomas, as shown in Table1. These gbMSCs from astrocytomas and glioblastomas showed similar classical MSC characteristics in vitro. They displayed a fibroblastic morphology and grew adherent to flasks in standard medium (Fig. 1a). The flowcytometric analysis showed that the gbMSCs expressed MSC markers, including CD73, CD105, CD44, and CD90, but not CD31, CD34, CD14, NG2 and PDGF 3 $\mathrm{R}$; moreover, slight $\alpha$-SMA and desmin expression was observed (Fig. 1b). The potential of gbMSCs to differentiate into adipocytes, osteoblasts and chondrocytes was tested in vitro using specific stimuli to promote adipogenesis, osteogenesis and chondrogenesis, respectively. Adipogenic differentiation was observed with oil red $\mathrm{O}$ staining, osteogenic differentiation was observed with Alizarin red staining and chondrogenic differentiation was observed with Alcian blue staining (Fig. 1c). The gbMSCs were able to differentiate into adipocytes, osteoblasts and chondrocytes.

Similarly, CD90 ${ }^{\text {high }}$ and CD90 ${ }^{\text {low }}$ gbMSCs all showed typical adherent growth in vitro (Fig. 2a, b). gbMSCs associated with CD90 expression were verified by flowcytometric analysis (Fig. 2c, d). Additionally, we found that their growth was significantly different and that CD90 ${ }^{\text {low }}$ gbMSCs cultured in 10\%DMEM grew faster than $\mathrm{CD} 90^{\text {high }}$ gbMSCs in vitro (Fig. 2e). Furthermore, the migration capacity of the CD $90^{\text {low }}$ gbMSCs incubated in different conditioned media was significantly stronger than that of CD90 ${ }^{\text {high }}$ gbMSCs (Fig. 2f).

\section{$\mathrm{CD} 90^{\text {high }}$ gbMSCs significantly promote glioma progression in vitro}

To demonstrate that CD90 ${ }^{\text {high }}$ gbMSCs significantly promoted glioblastoma growth, migration and adhesion in vitro, experiments were performed using CCK-8, Transwell chamber and adhesion assays, respectively. U87 cells cultured in $\mathrm{CD} 90^{\text {high }} \mathrm{CM}$ exhibited a significantly greater migration ability than cells cultured in CD90 ${ }^{\text {low }} \mathrm{CM}$ and $0 \%$ DMEM (Fig. 3a). Furthermore, U87 cells were incubated with serumfree medium, $\mathrm{CD} 90^{\text {low }}$ gbMSCs conditioned medium and CD90 $0^{\text {high }}$ gbMSCs conditioned medium (0\%DMEM, $\mathrm{CD} 90^{\text {low }} \mathrm{CM}$, and $\mathrm{CD} 90^{\text {high }} \mathrm{CM}$, respectively). We found 

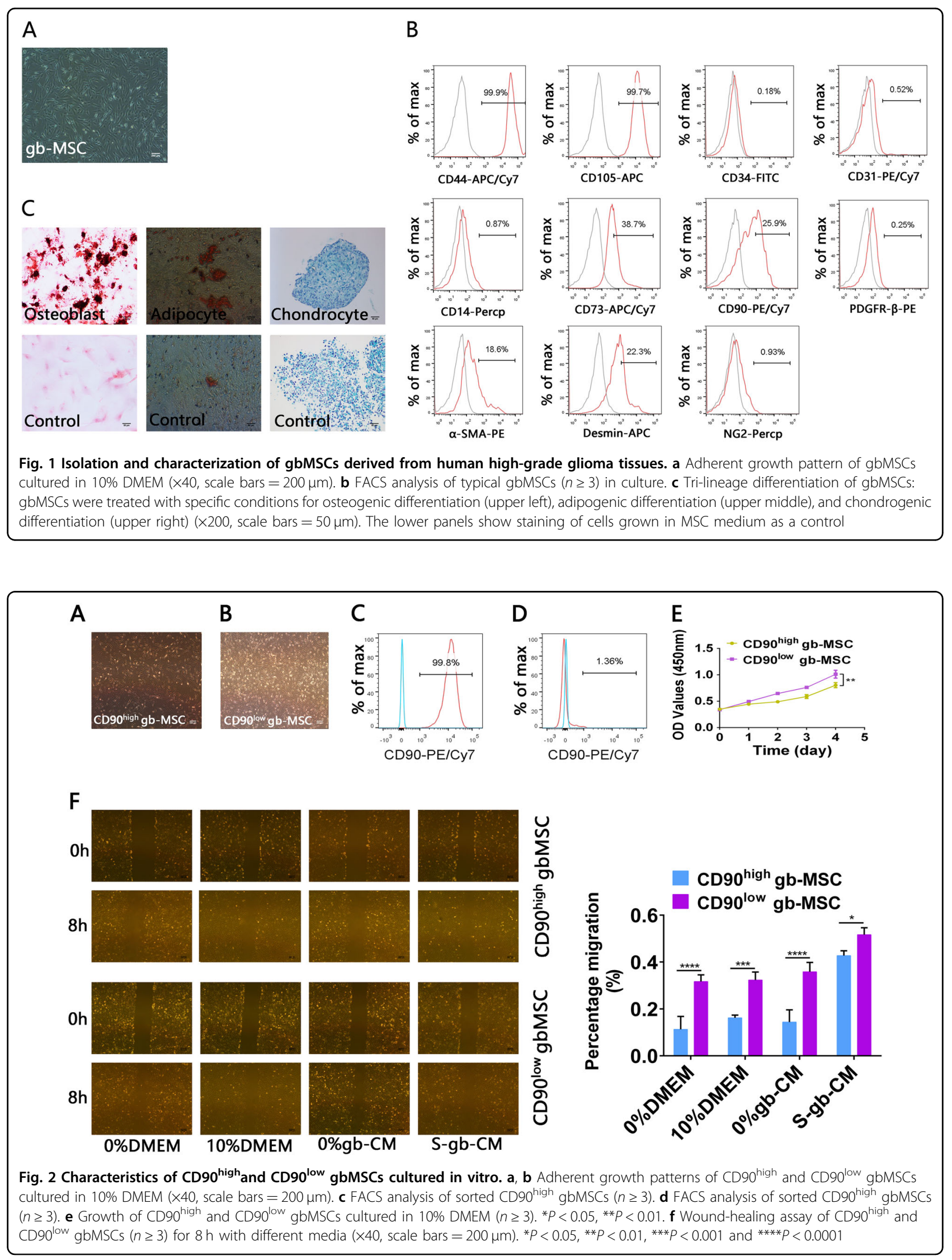

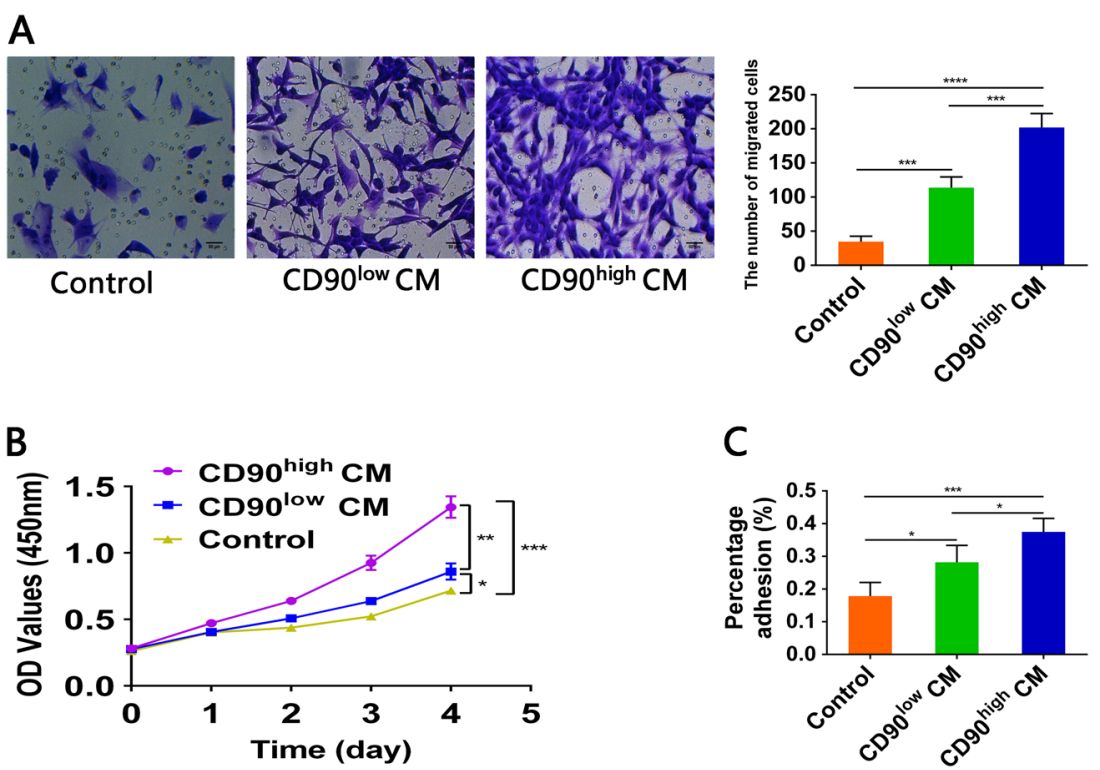

Fig. 3 The migration, proliferation and adhesion capacities of U87 cells incubated with different media in vitro. a Transwell assay of U87 cells cultured for $24 \mathrm{~h}$ in different media $(n \geq 3)$ (serum-free medium, $C D 90^{\text {low }} \mathrm{CM}$ and $C D 90^{\text {high }} \mathrm{CM}$ ). ${ }^{*} P<0.05,{ }^{* *} P<0.01,{ }^{* * *} P<0.001$ and ${ }^{* * * *} P<0.0001$. Serum-free medium was used as a control. b CCK8 assay of U87 cells $(n \geq 3)$ to evaluate proliferation in different media in vitro. U87 cells were incubated in $0 \% \mathrm{DMEM}, \mathrm{CD} 90^{\text {high }} \mathrm{CM}$ and $\mathrm{CD} 90^{\mathrm{low}} \mathrm{CM}$. ${ }^{*} P<0.05,{ }^{* *} P<0.01,{ }^{* * *} P<0.001$. Serum-free medium was used as a control. c Adhesion assay to estimate the effect of $0 \% \mathrm{DMEM}, \mathrm{CD} 90^{\text {high }} \mathrm{CM}$ and $\mathrm{CD} 90^{\text {low }} \mathrm{CM}$ on U87 cell adhesion. $(n \geq 3){ }^{*} P<0.05,{ }^{* *} P<0.01$, ${ }^{* *} P<0.001$. Serum-free medium were used as a control

that the proliferation ability of the U87 cells was significantly increased when incubated in $\mathrm{CD} 90^{\text {high }} \mathrm{CM}$ compared to that of the cells incubated in CD90 ${ }^{\text {low }} \mathrm{CM}$ and $0 \% \mathrm{DMEM}$ (Fig. 3b). In addition, the adhesion assay revealed that the $\mathrm{CD} 90^{\text {high }} \mathrm{CM}$ significantly enhanced the adhesive capacity of the U87 cells compared to that of the $\mathrm{CD} 90^{\text {low }} \mathrm{CM}$ and $0 \%$ DMEM (Fig. 3c).

\section{CD90 ${ }^{\text {low }}$ gbMSCs show strong angiogenesis and contribute} to new tube formation in vitro

The involvement of MSC-derived human glioma in neovascularization is well established ${ }^{6}$. Thus, we focused on studies of the vascular formation ability of the gbMSC subtypes in glioblastoma-conditioned media. We found that tube formation at $6 \mathrm{~h}$ was significantly increased in the CD $90^{\text {low }}$ gbMSCs incubated in different media (0\%DMEM, 10\%DMEM, 0\%gb-CM, and S-gb-CM) compared to that of their $\mathrm{CD} 90^{\text {high }}$ counterparts. The total tube segment lengths were also quantified; the tube segment lengths of the $\mathrm{CD} 90^{\text {low }}$ gbMSCs were significantly longer than those of their $\mathrm{CD} 90^{\text {high }}$ counterparts (Fig. 4a).

To study the capacity for angiogenesis generated by HUVECs cultured in the different media, HUVECs were seeded into wells and incubated with 0\%DMEM, CD90 ${ }^{\text {low }} \mathrm{CM}$ and $\mathrm{CD} 90^{\text {high }} \mathrm{CM}$. The tube networks were photographed at $6 \mathrm{~h}$ and analysed. The results showed the that angiogenic capacity of HUVECs cultured in $\mathrm{CD} 90^{\text {low }} \mathrm{CM}$ was significantly greater than that of the cells cultured in CD90 high $\mathrm{CM}$ and 0\%DMEM (Fig. 4b).

Attachment of pericytes to ECs helps maintain and stabilize capillary-like structures. Therefore, we sought to elucidate the attachment capacity of $\mathrm{CD} 90^{\text {low }}$ and CD90 ${ }^{\text {high }}$ gbMSC-derived pericytes. Calcein AM-labelled CD90 ${ }^{\text {low }}$ gbMSCs and HUVECs (1:2) and Calcein AMlabelled CD90 $0^{\text {high }}$ gbMSCs and HUVECs (1:2) were co-seeded into the same medium and photographed at $6 \mathrm{~h}$. The tube formation analyses showed that the attachment capacity of the $\mathrm{CD} 90^{\text {low }}$ gbMSC-derived pericytes was better than that of $\mathrm{CD} 90^{\text {high }}$ gbMSC-derived pericytes (Fig. 4c).

\section{Different functions of CD90 high and CD90 low $\mathrm{gbMSCs}$ in vivo}

To demonstrate that $\mathrm{CD} 90^{\text {high }} \mathrm{CM}$ and $\mathrm{CD} 90^{\text {low }} \mathrm{CM}$ had different functions in vivo, U87 cells with CD90 ${ }^{\text {high }}$ $\mathrm{CM}$ and $\mathrm{CD} 90^{\text {low }} \mathrm{CM}$ were implanted simultaneously into the brains of mice ( $N=6$ mice/group). The tumour size was significantly larger with $\mathrm{CD} 90^{\text {high }} \mathrm{CM}$ than with CD90 ${ }^{\text {low }} \mathrm{CM}$ (Fig. 5a), indicating that $\mathrm{CD} 90^{\text {high }} \mathrm{CM}$ increased the proliferation and/or tumourigenesis of U87 cells in vivo. CD31 expression in the CD90 ${ }^{\text {low }} \mathrm{CM}$ tumour specimens was significantly higher than that of 
A
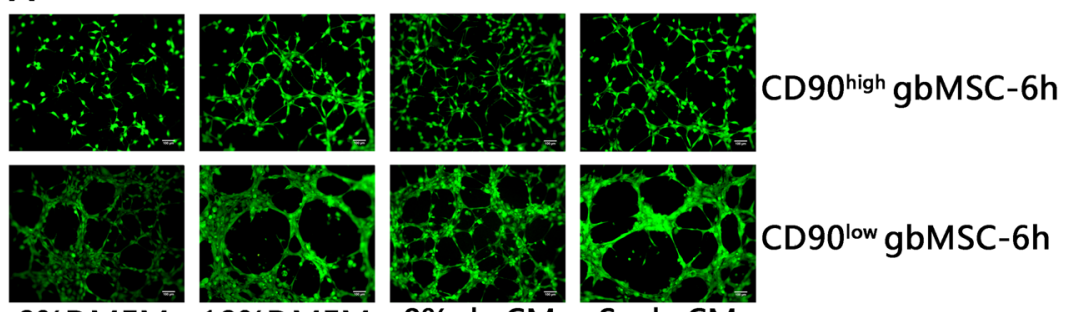

CD90 ${ }^{\text {low }}$ gbMSC- $6 \mathrm{~h}$

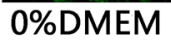

10\%DMEM

$0 \% g b-C M$

S-gb-CM

B

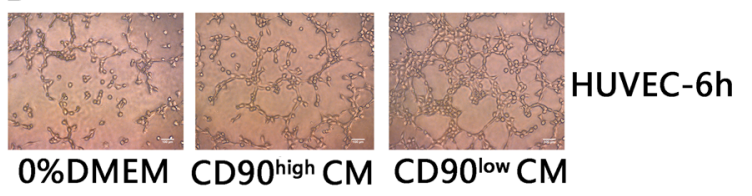

C

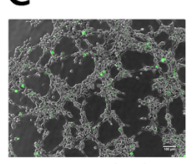

CD90 ${ }^{\text {high }}$

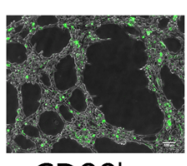

$6 \mathrm{~h}$
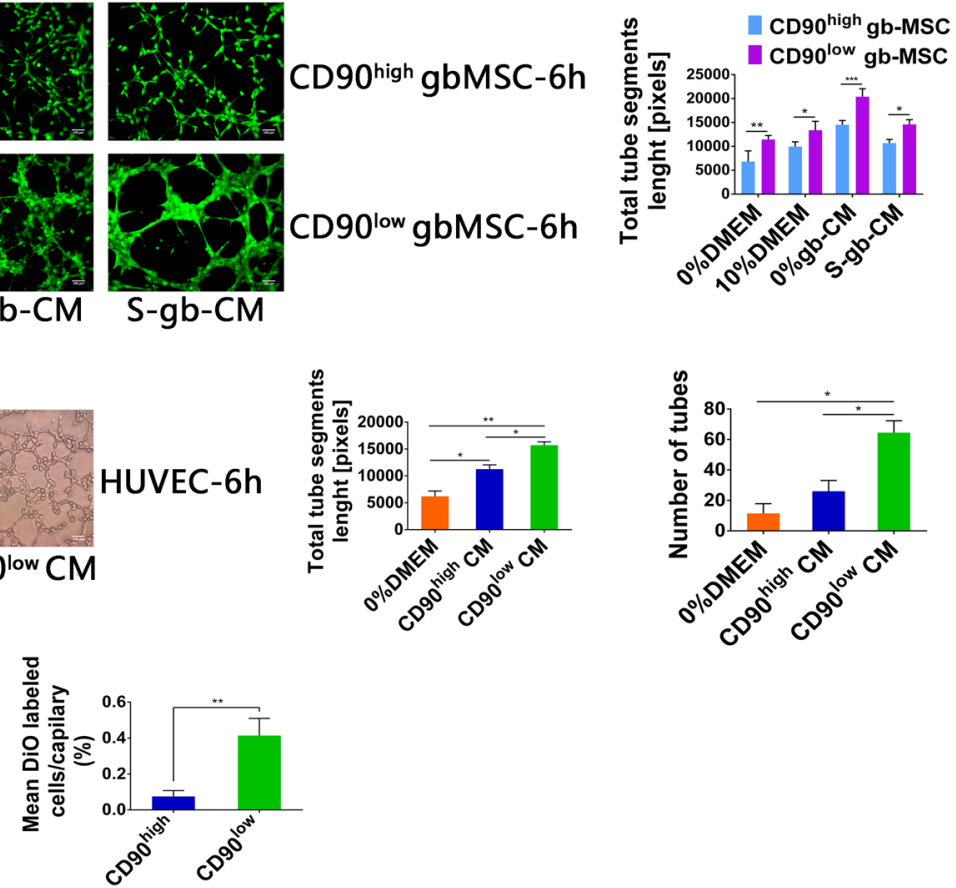

Fig. 4 Tube formation capacity of gbMSCs and HUVECs incubated in different media. a Angiogenic capacity of CD90 high and CD90 low gbMSCs cultured in 0\%DMEM, 10\%DMEM, 0\%gb-CM and S-gb-CM for $6 \mathrm{~h}$ on Matrigel $(\times 100$, scale bars $=100 \mu \mathrm{m}) .(n \geq 3){ }^{*} P<0.05$, ${ }^{*} P<0.01,{ }^{* * *} P<0.001$. b Angiogenic capacity of HUVECs cultured in 0\%DMEM, CD90 high $\mathrm{CM}$ and CD90 ${ }^{\text {low }} \mathrm{CM}$ for $6 \mathrm{~h}$ on Matrigel $(\times 100$, scale bars $=100 \mu \mathrm{m})$. ( $n \geq 3$ ) ${ }^{*} P<0.05,{ }^{* *} P<0.01$. c Attachment capacity of DiO-labelled CD90 ${ }^{\text {low }}$ and CD90 ${ }^{\text {high }}$ gbMSCs onto vascular structures formed by HUVECs in 0\%gb-CM $(\times 100$, scale bars $=100 \mu \mathrm{m}) .(n \geq 3) * P<0.05$ and ${ }^{* *} P<0.01$

their CD90high CM counterparts, whereas Ki-67 expression was significantly higher in the CD90 ${ }^{\text {high }} \mathrm{CM}$ tumour specimens than CD90 ${ }^{\text {low }} \mathrm{CM}$ counterparts (Fig. 5b). However, the survival time of the mice implanted with U87 cells co-cultured with $\mathrm{CD} 90^{\text {high }} \mathrm{CM}$ was not significantly shorter than that of mice implanted with U87 cells cultured in $\mathrm{CD} 90^{\text {low }} \mathrm{CM}$ (Fig. 5c). Additionally, we found that $\mathrm{CD} 90^{-} \mathrm{CD} 105^{+}$cells were mainly located in the vessel walls, whereas $\mathrm{CD} 105^{+} \mathrm{CD} 90^{+}$gbMSCs were located around the tumour parenchyma specimens in human glioblastomas (Fig. 5d). Moreover, the overall survival of patients with gliomas from TCGA database was not significantly different when the patients were group based on their CD90 expression levels (Fig. 5e).

\section{Secretion of factors related to $\mathrm{CD} 90^{\text {high }}$ and $\mathrm{CD} 90^{\text {low }}$ gbMSCs}

To analyse the secretion of several factors in different media, supernatants were collected and evaluated by ELISA. We found that the VEGF, FGF-2, and IL-6 levels were higher in the $\mathrm{CD}^{\circ} 0^{\text {low }} \mathrm{CM}$ than in the $\mathrm{CD} 90^{\text {high }} \mathrm{CM}$ and $0 \%$ DMEM (Fig. 6a-c). Conversely, the SDF-1 $\alpha$, CCL5, and MMP9 levels were higher in the CD90 ${ }^{\text {high }} \mathrm{CM}$ than in the CD90 ${ }^{\text {low }} \mathrm{CM}$ and 0\%DMEM (Fig. 6d-f).
Differential IncRNA and mRNA expression in the CD90 high and $\mathrm{CD} 90^{\text {low }}$ gbMSCs

Clariom D analysis of the CD90high and CD90 ${ }^{\text {low }}$ gbMSCs cultured in standard medium revealed different lncRNA and mRNA expression profiles. Subsequently, a test was performed to identify differentially expressed genes between the CD90 $0^{\text {high }}$ and CD90 ${ }^{\text {low }}$ gbMSCs, and a total of 4977 genes (2055 up regulated and 2922 down regulated in the $\mathrm{CD} 90^{\text {high }}$ gbMSCs) were identified (Fig. 7a). Differentially expressed mRNA target genes were predicted using TargetScan, IncRNA.org and the LnRDBA database, and the results were applied to a gene ontology (GO) term analysis (Fig. 7b), including the biological process (BP), molecular function (MF) and cellular component (CC) categories. The predicted target genes were enriched in cell migration, proliferation, adhesion and angiogenesis.

\section{Discussion}

In 1966, the existence of MSCs in bone marrow was first reported by Friendenstein et al. ${ }^{11}$. Thereafter, MSCs were widely and gradually researched in several fields, but studies were limited by the lack of a definitive marker for MSCs, which meant that the cell type could only 

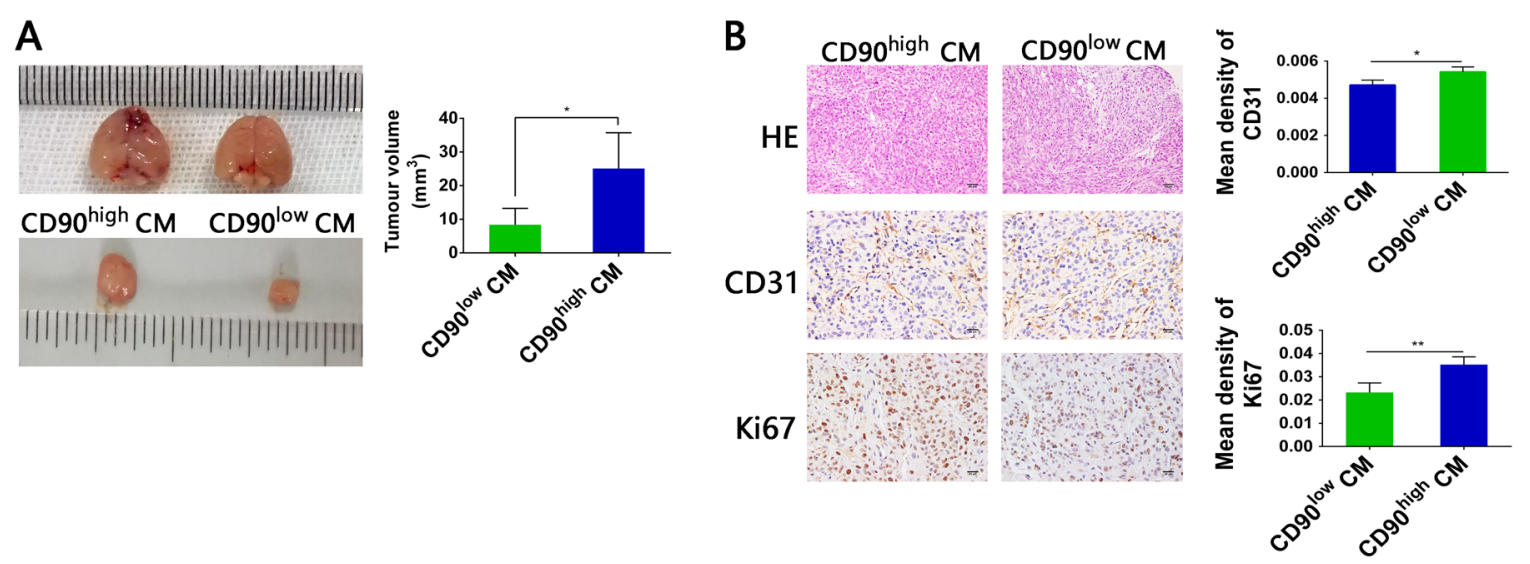

C

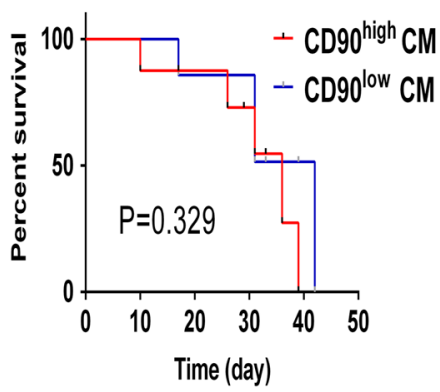

D

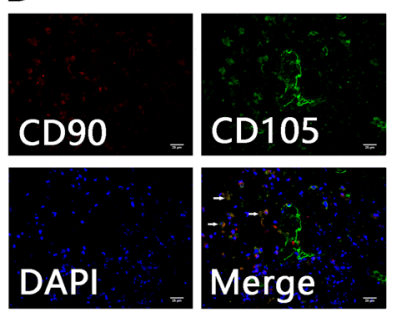

E

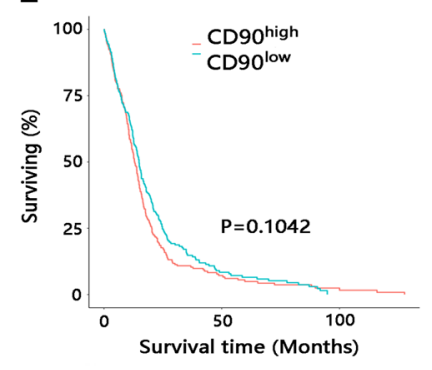

Fig. 5 Conditioned media from $\mathrm{CD} 90^{\text {high }}$ and $\mathrm{CD} 90^{\text {low }}$ gbMSCs have different functions in vivo. a Representative mice from intracranial xenograft experiments in which U87 cells with CD90 ${ }^{\text {high }} \mathrm{CM}$ (left) or U87 cells with CD90 ${ }^{\text {low }} \mathrm{CM}$ (right) were injected into the right frontal lobes of nude mice. Obviously, the sizes of the $C D 90^{\text {high }} \mathrm{CM}$ group tumours were greater than those of their CD90 ${ }^{\text {low }} \mathrm{CM}$ counterparts. ${ }^{*} P<0.05$. $\mathbf{b}$ Both the CD90 high $C M$ and CD90 ${ }^{\text {low }}$ CM tumour sections were stained with HE ( $\times 200$, scale bars $\left.=50 \mu m\right)$. In the CD90 ${ }^{\text {high }}$ CM and CD90 low $C M$ tumour tissues, IHC was employed to detect CD31 and Ki-67 expression $(\times 400$, scale bars $=25 \mu \mathrm{m})$. ( $n \geq 3) *{ }^{*} P<0.05$, ** $P<0.01$. c Survival curves of glioma-bearing mice. The survival times of mice implanted with U87 cells cultured with CD90 ${ }^{\text {high }}$ CM were not significantly shorter than those of mice implanted with $U 87$ cells cultured in CD90 ${ }^{\text {low }}$ CM. d Double staining for CD105 (green) and CD90 (red) revealed that CD105 ${ }^{+}$CD90 ${ }^{-}$cells were located in the

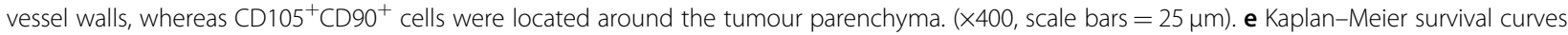
for patients with low and high CD90 expression. The survival of glioma patients with different CD90 expression levels in TCGA database was not significantly different

be defined in terms of cellular morphology, surface markers and differentiation potential. In 2006, the International Society for Cellular Therapy (ISCT) defined the minimal criteria for MSCs according to their biological features $^{12}$. Positive CD90 expression is one of the minimal criteria used to define MSCs, and MSCs expressing high CD90 levels can be found in tissues including bone marrow and adipose tissue ${ }^{13}$. In gliomas, tumour cells recruit MSCs from different tissues and corrupt them into gbMSCs to promote tumour progression ${ }^{14}$. Compared to their main BM-MSC resources, gbMSCs harbour genetic alterations, of which CD90 expression is one difference ${ }^{6}$. In the current study, we found two subpopulations $\left(\mathrm{CD} 90^{\text {high }}\right.$ gbMSCs and CD90 ${ }^{\text {low }}$ gbMSCs) that could be sorted from all fresh glioma tissues (WHO II-IV gliomas). CD90 ${ }^{\text {low }}$ gbMSCs were more abundant than CD $90^{\text {high }}$ gbMSCs in the same glioma tissues. With the exception of CD90 expression, these two subpopulations showed similar cellular morphologies. The CD $90^{\text {low }}$ gbMSCs had stronger proliferation and migration abilities than the CD90 high gbMSCs. Previous literature reported that angiogenic stimuli and mechanical stress led to a loss of CD90 expression in MSCs ${ }^{15,16}$. Our previous study reported that $\mathrm{CD} 90^{\text {low }}$ gbMSCs could differentiate into pericytes and contribute to angiogenesis in the malignant glioma microenvironment ${ }^{6}$. Thus, tumour cells may influence CD90 expression on MSCs recruited to a glioma for angiogenesis, but tumour cells may recruit different gbMSC subpopulations from different resources for different hallmarks of malignant gliomas.

To date, MSCs from different sources have shown different abilities to promote or suppress the growth of glioma cells under different conditions ${ }^{17-21}$. In gliomas, tumour cells do not recruit MSCs into the tumour microenvironment as bystanders or inhibitorsof progression $^{5,14}$. Previous studies found that high percentages of gbMSCs in tumour samples correlated with poor outcomes of patients with high-grade gliomas. Additionally, 

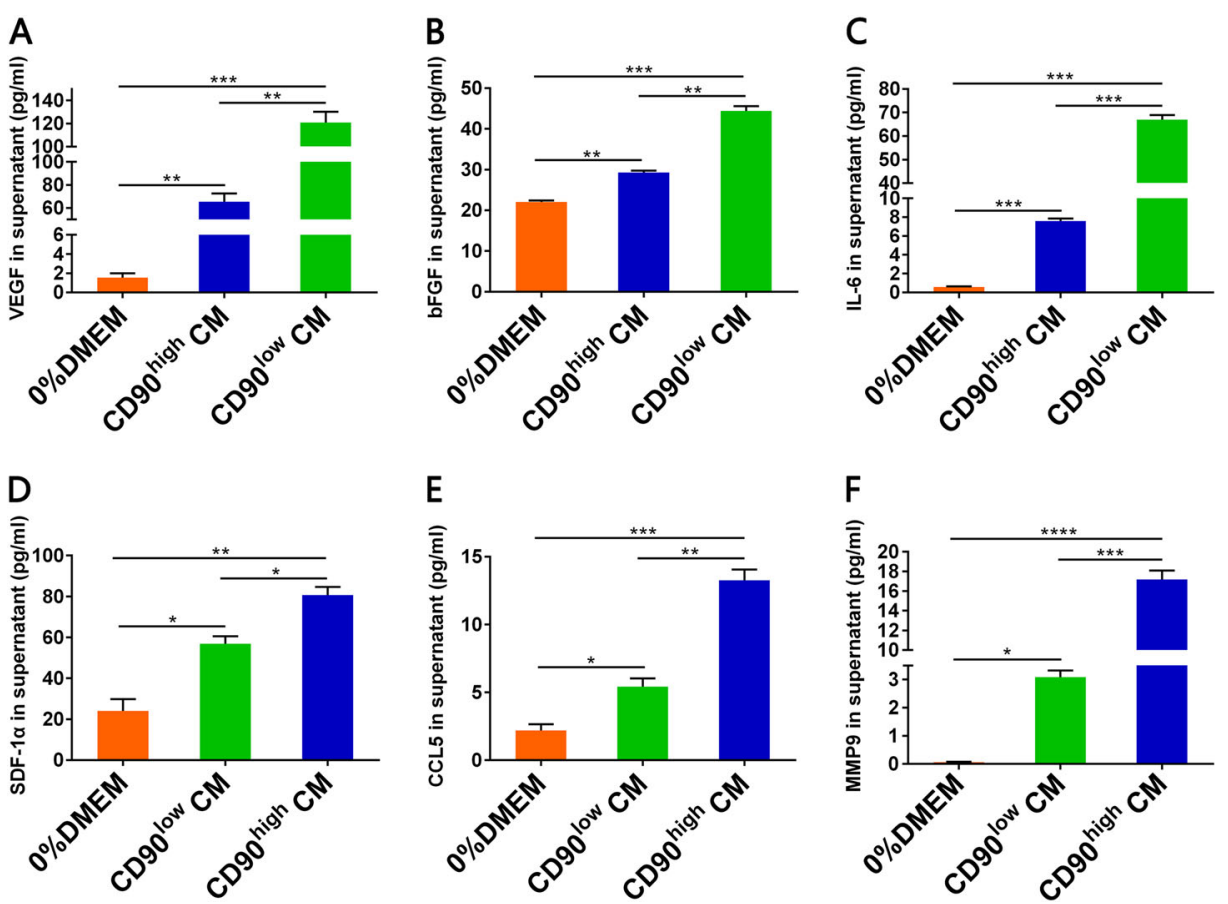

Fig. 6 The VEGF, IL-6, bFGF, MMP9, CCL5 and SDF-1alevels in different treatment media by ELISA. a The VEGF $(n \geq 3)$ levels were significantly higher in $\mathrm{CD} 90^{\text {low }} \mathrm{CM}$ compared to those in CD90 high $\mathrm{CM}$ and 0\%DMEM. $\mathbf{b}$ The bFGF $(n \geq 3)$ levels were significantly higher in CD90 ${ }^{\text {low }} \mathrm{CM}$ compared to those in CD90 high CM and 0\%DMEM. c The IL-6 $(n \geq 3)$ levels were significantly higher in CD90 low CM compared to those in CD90high $C M$ and $0 \%$ DMEM. * $\mathbf{d}$ The SDF-1a $(n \geq 3)$ levels were higher in CD90 high CM compared to those in CD90 low CM and 0\%DMEM. e The CCL5 ( $n \geq 3)$ levels were higher in $\mathrm{CD} 90^{\text {high }} \mathrm{CM}$ compared to those in CD90 ${ }^{\text {low }} \mathrm{CM}$ and 0\%DMEM. f The MMP9 $(n \geq 3)$ levels were significantly higher in CD90high $C M$ compared to those in $\mathrm{CD}^{\text {low }} \mathrm{CM}$ and $0 \% \mathrm{DMEM} . P<0.05,{ }^{* *} P<0.01,{ }^{* * *} P<0.001$ and ${ }^{* * * *} P<0.0001$

A

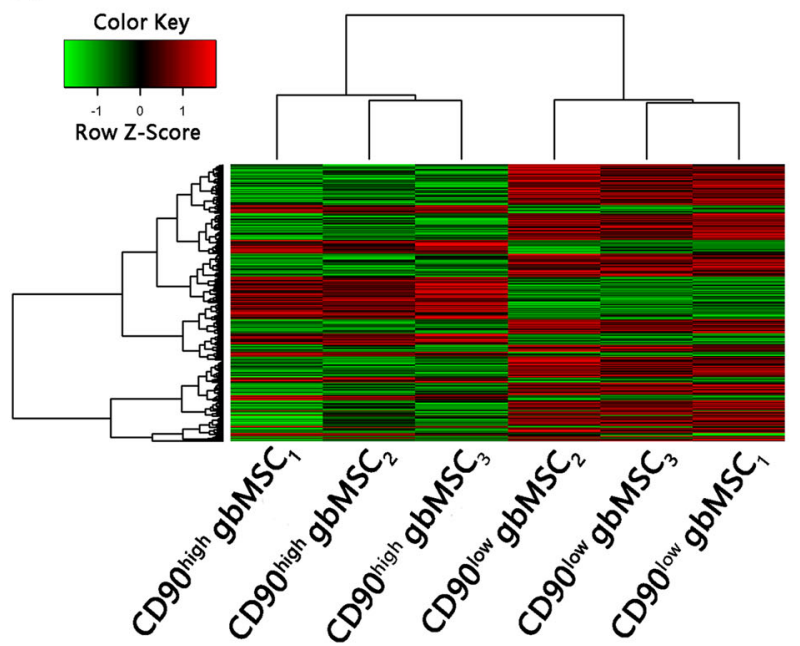

B

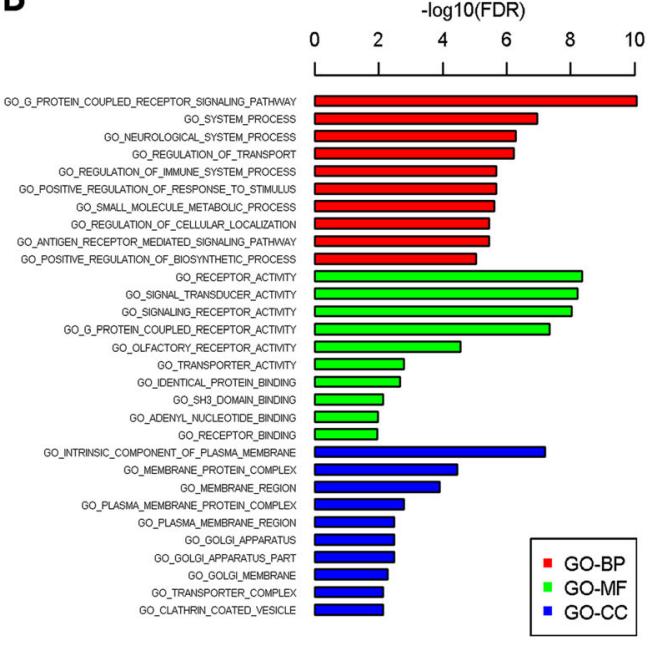

Fig. 7 Clariom D expression profiles of CD90 ${ }^{\text {high }}$ and CD90 low gbMSCs $(\boldsymbol{n}=\mathbf{3})$. a Heatmap of differentially expressed IncRNAs from a microarray assay performed on $\mathrm{CD} 90^{\text {high }}$ and $\mathrm{CD} 90^{\text {low }} \mathrm{gbMSCs}$. 'Red' indicates high relative expression, and 'green' indicates low relative expression. b $\mathrm{GO}$ terms for the predicted targeted genes. $P<0.05$ using the two-sided Fisher's exact test was defined as statistically significant 
gbMSCs could increase the tumourigenicity and maintain the stemness of glioma stem cells ${ }^{9}$. In the current study, we investigated the different roles of two subpopulations $\left(\mathrm{CD} 90^{\text {high }}\right.$ and $\mathrm{CD} 90^{\text {low }}$ gbMSCs) in aggressive progression of gliomas. Conditioned medium from $\mathrm{CD} 90^{\text {high }}$ gbMSCs induced faster proliferation and stronger migration and adherence of U87 cells in vitro, and injection of conditioned medium from CD $90^{\text {high }}$ gbMSCs resulted in a larger tumour volume and more Ki-67labelled tumour cells in an animal model. Conversely, the $\mathrm{CD} 90^{\text {low }}$ gbMSCs had a strong ability to differentiate into pericytes and induce tube formation in vitro, and conditioned medium from the $\mathrm{CD} 90^{\text {low }}$ gbMSCs induced more capillary-like endothelial cell structures. In animal models, injection of conditioned medium from $\mathrm{CD} 90^{\text {low }}$ gbMSCs induced more CD31-expressing vessels. In human glioblastoma tissues, $\mathrm{CD} 105^{+} \mathrm{CD} 90^{-}$cells were located in the vessel walls, and $\mathrm{CD} 105^{+} \mathrm{CD} 90^{+}$cells were located around the tumour parenchyma. These data suggested that $\mathrm{CD} 90^{\text {high }}$ gbMSCs mainly promoted tumour cell proliferation, where as CD90 low gbMSCs mainly differentiated into pericytes and contributed to angiogenesis. However, gbMSCs are not the sole players in the tumourigenicity of malignant gliomas, and the overall survival of patients with gliomas in TCGA database and tumour-bearing mice is not significantly different between groups with different CD90 expression levels.

Cytokines are a very important component of the crosstalk between tumour cells and the tumour microenvironment ${ }^{3,6}$. Previous studies showed that cytokines and secreted exosomes were important for the effect of gbMSCs on the tumourigenicity of malignant gliomas ${ }^{9,22}$. Therefore, cytokines and related lnRNAs were compared between $\mathrm{CD} 90^{\text {high }}$ and $\mathrm{CD} 90^{\text {low }}$ gbMSCs in the current study. $C D 90^{\text {low }}$ gbMSCs produced higher levels of the angiogenesis factors VEGF, bFGF and IL-6, and CD $90^{\text {high }}$ gbMSCs produced higher levels of the growth factors SDF- $1 \alpha$, CCL5, and MMP9. These results are consistent with previous findings ${ }^{23-28}$. To explore their gene profiles, we analyse differences in expression based on the Clariom $\mathrm{D}$ assay and the predicted gene ontologies of the $\mathrm{CD} 90^{\text {high }}$ and $\mathrm{CD} 90^{\text {low }}$ gbMSCs. We identified specific lncRNA, mRNA and target gene pairs in the $\mathrm{CD} 90^{\text {high }}$ and $\mathrm{CD} 90^{\text {low }}$ gbMSCs. Previous reports indicated important links between the G protein-coupled receptor pathway and tumour proliferation ${ }^{29-32}$ and angiogenesis ${ }^{33-35}$. In future studies, we will identify the specific lncRNA, mRNA and target gene pairs that are significantly different between the $\mathrm{CD} 90^{\text {low }}$ and $\mathrm{CD} 90^{\text {high }}$ gbMSCs and promote tumour proliferation and angiogenesis.

In conclusion, we elaborately sorted two subpopulations (CD90 $0^{\text {high }}$ and CD90 ${ }^{\text {low }}$ gbMSCs) from gbMSCs. Both subpopulations had cellular morphologies and surface markers similar to those of classical MSCs but showed slightly different biological features and played enormously different roles in the glioma microenvironment. Both in vivo and in vitro, CD90 ${ }^{\text {high }}$ gbMSCs significantly promoted glioma cell growth, and the CD90 ${ }^{\text {low }}$ gbMSCs promoted angiogenesis via pericyte transition. Additionally, we provided evidence that the expression patterns of secreted factors and related lncRNAs in these two subpopulations might affect their roles in glioma progression. However, determining the underlying mechanism requires further exploration in more detail. Therefore, these results revealed that future therapies targeting the two distinct gbMSC subpopulations should use different strategies.

\section{Acknowledgements}

This work was supported by a grant from the National Natural Science Foundation of China (No. 81572488) and grants from the Science and Technology Department of Hubei Province (2015CFB458 and 2017CFB268).

\section{Author details}

${ }^{1}$ Department of Neurosurgery,Union Hospital, Tongji Medical College, Huazhong University of Science and Technology, Wuhan 430022, China. ${ }^{2}$ Department of Cardiology, Beijing Anzhen Hospital, Capital Medical University, No. 2, Anzhen Road, Chaoyang District, Beijing 100029, China. ${ }^{3}$ Institute of Infection and Immunology, Union Hospital, Tongji Medical College, Huazhong University of Science and Technology, Wuhan 430022, China. ${ }^{4}$ Department of Neurosurgery, Faculty of Medicine, Helwan University, Cairo 11435, Egypt. ${ }^{5}$ Jiangsu Key Lab of Medical Optics, Suzhou Institute of Biomedical Engineering and Technology, Chinese Academy of Sciences, Suzhou 215163, China

\section{Conflict of interest}

The authors declare that they have no conflict of interest.

\section{Publisher's note}

Springer Nature remains neutral with regard to jurisdictional claims in published maps and institutional affiliations.

Received: 17 July 2018 Revised: 8 October 2018 Accepted: 11 October 2018 Published online: 27 October 2018

\section{References}

1. Holland, E. C. Glioblastoma multiforme: the terminator. Proc. Natl Acad. Sci. USA 97, 6242-6244 (2000).

2. Fu, P. et al. Bevacizumab treatment for newly diagnosed glioblastoma: Systematic review and meta-analysis of clinical trials. Mol. Clin. Oncol. 4, 833-838 (2016).

3. Catalano, V. et al. Tumor and its microenvironment: a synergistic interplay. Semin. Cancer Biol. 23, 522-532 (2013).

4. Wu, Y., Lu, Y., Chen, W., Fu, J. \& Fan, R. In silico experimentation of glioma microenvironment development and anti-tumor therapy. PloSComputBiol 8 , e1002355 (2012).

5. $\mathrm{Xu}, \mathrm{F}$. et al. Chemokines mediate mesenchymal stem cell migration toward gliomas in vitro. Oncol. Rep. 23, 1561-1567 (2010).

6. Yi, D. et al. Human glioblastoma-derived mesenchymal stem cell to pericytes transition and angiogenic capacity in glioblastoma microenvironment. Cell. Physiol. Biochem. 46, 279-290 (2018).

7. Guo, K. T. et al. The expression of Wnt-inhibitor DKK1 (Dickkopf 1) is determined by intercellular crosstalk and hypoxia in human malignant gliomas. J. Cancer Res. Clin. Oncol. 140, 1261-1270 (2014).

8. Shahar, T. et al. Percentage of mesenchymal stem cells in high-grade glioma tumor samples correlates with patient survival. Neuro. Oncol. 19, 660-668 (2017). 
9. Hossain, A. et al. Mesenchymal stem cells isolated from human gliomas increase proliferation and maintain stemness of glioma stem cells through the IL-6/gp130/STAT3 pathway. Stem Cells 33, 2400-2415 (2015).

10. Svensson, A., Ramos-Moreno, T., Eberstal, S., Scheding, S. \& Bengzon, J. Identification of two distinct mesenchymal stromal cell populations in human malignant glioma. J. Neurooncol. 131, 245-254 (2017).

11. Friedenstein, A. J., Piatetzky, S. II \& Petrakova, K. V. Osteogenesis in transplants of bone marrow cells. J. Embryol. Exp. 16, 581-390 (1966)

12. Dominici, M. et al. Minimal criteria for defining multipotent mesenchymal stromal cells. The International Society for Cellular Therapy position statement. Cytotherapy 12, 315-317 (2006).

13. May Al-Nbaheen, Rv et al. Human stromal (mesenchymal) stem cells from bone marrow, adipose tissue and skin exhibit differences in molecular phenotype and differentiation potential. Stem Cell Rev. Rep. 9, 32-43 (2013).

14. Birnbaum, T. et al. Malignant gliomas actively recruit bone marrow stromal cells by secreting angiogenic cytokines. J. Neurooncol. 83, 241-247 (2007).

15. Campioni, D., Lanza, F., Moretti, S., Ferrari, L. \& Cuneo, A. Loss of Thy-1 (CD90) antigen expression on mesenchymal stromal cells from hematologic malignancies is induced by in vitro angiogenic stimuli and is associated with peculiar functional and phenotypic characteristics. Cytotherapy 10, 69-82 (2008).

16. Wiesmann, A., Buhring, H. J., Mentrup, C. \& Wiesmann, H. P. Decreased CD90 expression in human mesenchymal stem cells by applying mechanical stimulation. Head Face Med. 2, 8 (2006).

17. Akimoto, $\mathrm{K}$. et al. Umbilical cord blood-derived mesenchymal stem cells inhibit, but adipose tissue-derived mesenchymal stem cells promote, glioblastoma multiforme proliferation. Stem Cells Dev. 22, 1370-1386 (2013).

18. Ho, I. A. et al. Human bone marrow-derived mesenchymal stem cells suppress human glioma growth through inhibition of angiogenesis. Stem Cells $\mathbf{3 1}$, 146-155 (2013).

19. Yang, C. et al. Conditioned media from human adipose tissue-derived mesenchymal stem cells and umbilical cord-derived mesenchymal stem cells efficiently induced the apoptosis and differentiation in human glioma cell lines in vitro. Biomed. Res. Int. 2014, 109389 (2014).

20. Pacioni, S. et al. Human mesenchymal stromal cells inhibit tumor growth in orthotopic glioblastoma xenografts. Stem Cell Res. Ther. 8, 53 (2017).

21. Iser, I. C. et al. Conditioned medium from adipose-derived stem cells (ADSCs) promotes epithelial-to-mesenchymal-like transition (EMT-like) in glioma cells in vitro. Mol. Neurobiol. 53, 7184-7199 (2016).
22. Figueroa, J. et al. Exosomes from glioma-associated mesenchymal stem cells increase the tumorigenicity of glioma stem-like cells via transfer of miR-1587. Cancer Res. 77, 5808-5819 (2017).

23. Nagasaki, T. et al. Interleukin- 6 released by colon cancer-associated fibroblasts is critical for tumour angiogenesis: anti-interleukin-6 receptor antibody suppressed angiogenesis and inhibited tumour-stroma interaction. Br. J. Cancer 110, 469-478 (2014).

24. Maru, S. V. et al. Chemokine production and chemokine receptor expression by human glioma cells: role of CXCL10 in tumour cell proliferation. J. Neuroimmunol. 199, 35-45 (2008).

25. LV, B. et al. CXCR4Signaling induced epithelial-mesenchymal transition by PI3KJAKT and ERK pathways in glioblastoma. Mol. Neurobiol. 52, 1263-1268 (2015).

26. Zhao, L. et al. Critical roles of chemokine receptor CCR5 in regulating glioblastoma proliferation and invasion. Acta Biochim. Sin. 47, 890-898 (2015).

27. Xue, Q. et al. High expression of MMP9 in glioma affects cell proliferation and is associated with patient survival rates. Oncol. Lett. 13, 1325-1330 (2017).

28. Wang, M., Wang, T., Liu, S., Yoshida, D. \& Teramoto, A. The expression of matrix metalloproteinase-2 and -9 in human gliomas of different pathological grades. Brain Tumor Pathol. 20, 65-72 (2003).

29. $\mathrm{Wu}, \mathrm{Q}$. et al. Identification of G-protein-coupled receptor 120 as a tumorpromoting receptor that induces angiogenesis and migration in human colorectal carcinoma. Oncogene 32, 5541-5550 (2013).

30. Song, Y., Li, A., Zhang, L. \& Duan, L. Expression of G protein-coupled receptor 56 is associated with tumor progression in non-small-cell lung carcinoma patients. Onco. Targets Ther. 9, 4105-4112 (2016).

31. Zhang, X. et al. G protein-coupled receptor 87 (GPR87) promotes cell proliferation in human bladder cancer cells. Int. J. Mol. Sci. 16, 24319-24331 (2015).

32. Kaur, G. et al. G-protein coupled receptor kinase (GRK)-5 regulates proliferation of glioblastoma-derived stem cells. J. Clin. Neurosci. 20, 1014-1018 (2013).

33. Banerjee, R. et al. The G protein-coupled receptor GALR2 promotes angiogenesis in head and neck cancer. Mol. Cancer Ther. 13, 1323-1333 (2014).

34. Zhou, L. et al. G-protein-coupled receptor 30 mediates the effects of estrogen on endothelial cell tube formation in vitro. Int. J. Mol. Med. 39, 1461-1467 (2017).

35. Rivas, $\mathrm{V}$. et al. Developmental and tumoral vascularization is regulated by $\mathrm{G}$ protein-coupled receptor kinase 2. J. Clin. Invest. 123, 4714-4730 (2013). 